\title{
Modern Challenges for Early-Phase Clinical Trial Design and Biomarker Discovery in Metastatic Non-Small-Cell Lung Cancer
}

\author{
Antonio Rossi ${ }^{1, *}$, Sara Pilotto ${ }^{2}{ }^{(}$, Luisa Carbognin ${ }^{3}$, Miriam Grazia Ferrara ${ }^{4,5}{ }^{(}$, Lorenzo Belluomini ${ }^{2} \mathbb{C}$, \\ Gennaro Daniele ${ }^{6(D)}$ and Emilio Bria ${ }^{4,5}$ (D) \\ 1 Therapeutic Science \& Strategy Unit, IQVIA, 20124 Milan, Italy \\ 2 Medical Oncology, Department of Medicine, University of Verona, Azienda Ospedaliera Universitaria \\ Integrata (AOUI) di Verona, 37100 Verona, Italy; sara.pilotto@univr.it (S.P.); \\ lorenzo.belluomini08@gmail.com (L.B.) \\ 3 Department of Woman and Child Health and Public Health, Woman Health Area, Fondazione Policlinico \\ Universitario A. Gemelli IRCCS, 00100 Rome, Italy; luisa.carbognin@gmail.com \\ 4 Comprehensive Cancer Center, Fondazione Policlinico Universitario Agostino Gemelli IRCCS, \\ 00100 Rome, Italy; miriamgraziaferrara@gmail.com (M.G.F.); emilio.bria@unicatt.it (E.B.) \\ 5 Department of Translational Medicine and Surgery, Università Cattolica del Sacro Cuore, 00100 Rome, Italy \\ 6 Scientific Directorate, Fondazione Policlinico Universitario Agostino Gemelli IRCCS, 00100 Rome, Italy; \\ gennaro.daniele@policlinicogemelli.it \\ * Correspondence: arossi_it@yahoo.it; Tel.: +39-02-697-861
}

check for

updates

Citation: Rossi, A.; Pilotto, S.;

Carbognin, L.; Ferrara, M.G.;

Belluomini, L.; Daniele, G.; Bria, E.

Modern Challenges for Early-Phase

Clinical Trial Design and Biomarker Discovery in Metastatic

Non-Small-Cell Lung Cancer. J. Mol. Pathol. 2021, 2, 207-222. https://

doi.org/10.3390/jmp2030018

Academic Editor: Claudio Bellevicine

Received: 13 May 2021

Accepted: 18 June 2021

Published: 23 June 2021

Publisher's Note: MDPI stays neutral with regard to jurisdictional claims in published maps and institutional affiliations.

Copyright: (c) 2021 by the authors. Licensee MDPI, Basel, Switzerland. This article is an open access article distributed under the terms and conditions of the Creative Commons Attribution (CC BY) license (https:// creativecommons.org/licenses/by/ $4.0 /)$.

\begin{abstract}
Oncology research has changed extensively due to the possibility to categorize each cancer type into smaller subgroups based on histology and particularly on different genetic alterations due to their heterogeneity. The consequences of this heterogeneity are particularly evident in the management of metastatic non-small-cell lung cancer (NSCLC). This review will discuss the benefits and challenges of incorporating precision medicine into early- through late-phase metastatic NSCLC clinical trials, discussing examples of drug development programs in oncogene- and non-oncogeneaddicted NSCLC. The experiences of clinical development of crizotinib, gefitinib and osimertinib are depicted showing that when a targeted drug is administrated in a study population not selected by any biomarker, trials could produce negative results. However, the early detection of biomarkerdriven biology helps to obtain a greater benefit for a selected population and can reduce the required time for drug approval. Early clinical development programs involving nivolumab, pembrolizumab and avelumab, immune checkpoint inhibitors, taught us that, beyond safety and activity, the optimal selection of patients should be based on pre-specified biomarkers. Overall, the identification of predictive biomarkers is one of the greatest challenges of NSCLC research that should be optimized with solid methodological trial designs to maximize the clinical outcomes.
\end{abstract}

Keywords: clinical trials; immunotherapy; immune checkpoint inhibitors; non-small cell lung cancer; targeted therapy; tyrosine kinase inhibitors

\section{Introduction}

In oncology research, the clinical trials can fail more frequently than in any other diseases [1]. Despite most phase 3 trials being designed based on robust previous data sets, many fail to reach the primary endpoint after many years of work and high investments [2,3]. Thus, it is of paramount importance to understand why the results of these phase 3 trials were not as expected. A possible explanation could be the high heterogeneity that characterized each cancer type, both in inter-patients and intra-patient settings.

In the last few years, the oncology research has deeply changed due to the possibility to categorize each cancer type in smaller subgroups based on histology and particularly 
on different genetic alterations due to their heterogeneity. These led to a different reclassification of these diseases and each subgroup is characterized by different prognosis and responses to both standard and targeted treatments $[4,5]$.

The consequences of this heterogeneity are particularly evident in the management of metastatic non-small-cell lung cancer (NSCLC). The treatment of this disease passed from a "one size fits all" model to steps towards the "precision medicine" which can be defined as the right drug to the right patient at the right moment [6]. For instance, when approaching first-line treatment of metastatic NSCLC, to know the following biomarkers panel status is mandatory in order to address the best treatment approach: epidermal growth factor receptor (EGFR), B-Raf proto-oncogene, serine/threonine kinase (BRAF) V600E and MET exon 14 skipping mutations, anaplastic lymphoma kinase $(A L K)$, proto-oncogene tyrosineprotein kinase ROS (ROS1) and rearranged during transfection (RET) rearrangements, which are overall detected in about $25 \%$ of lung adenocarcinoma Caucasian patients who benefit from specific inhibitors. These subgroups of patients define the oncogene-addicted NSCLC. Another subgroup can be selected by the PD-L1 (programmed death ligand-1) tumor proportion score (TPS) expression $\geq 50 \%$, detected in about $25-30 \%$ of non-oncogeneaddicted NSCLC patients, which identifies the cases which can benefit from first-line single-agent pembrolizumab, an immunoglobulin (Ig) G4 anti-programmed cell death-1 (PD-1) monoclonal antibody (mAb) [7].

At times, the genomic aberrations are not cancer-specific, but can be detected in many types of cancers in which the same activity but also the same sensitivity to specific inhibitors occur. This is the case with neurotrophic tyrosine receptor kinase (NTRK) fusions, which are oncogenic drivers of various adult and pediatric malignancies. In this context, the identification of tumors harboring NTRK fusions is crucial, considering that the Food and Drug Administration (FDA) granted the approval as being tumor-agnostic for the first-generation TRK inhibitors, larotrectinib and entrectinib, for the treatment of these cancers in 2018 and 2019, respectively [8].

Thus, the use of predictive biomarkers to individualize treatment has revolutionized care in some cancer subtypes. In this context, it is clear that the traditional drug development track, from preclinical phase through phase 1, 2 up to phase 3 studies, is gradually fading out. The model of one cancer type, one companion diagnostic, one drug and one clinical trial, may not represent the most efficient use of resources in the current medical, scientific and economic settings. In the last few years, phase- 1 dose-escalation trials followed by large expansion cohorts and the emergence of new trial designs have also been frequently applied in order to establish strict collaboration between clinicians, pharmaceutical companies and regulatory agencies.

This review discusses the benefits and challenges of incorporating precision medicine into early- through late-phase metastatic NSCLC clinical trials, discussing examples of drug development programs in oncogene- and non-oncogene-addicted NSCLC.

\section{Modern Versus Old Early-Phase Clinical Trial Design: Lights and Shadows}

The drug development in the precision oncology era is everything but an efficient process. With the highest attrition rate and a very long duration [9], only in recent years has the process benefitted from a changing paradigm. The observation that the variation in prognosis among individuals is often greater than the average effect of a therapeutics prompts a change in the object of the drug development in identifying and assessing the efficacy of new drugs in homogenously selected patients as early as possible in their development [10]. For this goal, a new generation of clinical trials has been designed with the aim of demonstrating either the efficiency of the "personalized model" or the specific activity of a drug/combination in molecularly selected populations of patients (Figure 1). In this framework, the vertical dimension of the "classic" drug development (i.e., sequential succession of phases) left the place to a horizontal dimension in which the goals of the sequential phases are often shrunk into the same protocol/platform, and the classic compartmental drug development is transforming into a "liquid development" where the 
classical phases cannot be distinguished. Apparently, introducing a personalized approach since the early phase reduced the attrition rate, leading to an increased proportion of drugs having entered clinical development, finally causing an approval increase from $8.4 \%$ to $26 \%$ and reducing the time from first-in-human $(\mathrm{FIH})$ initiation and drug approval.

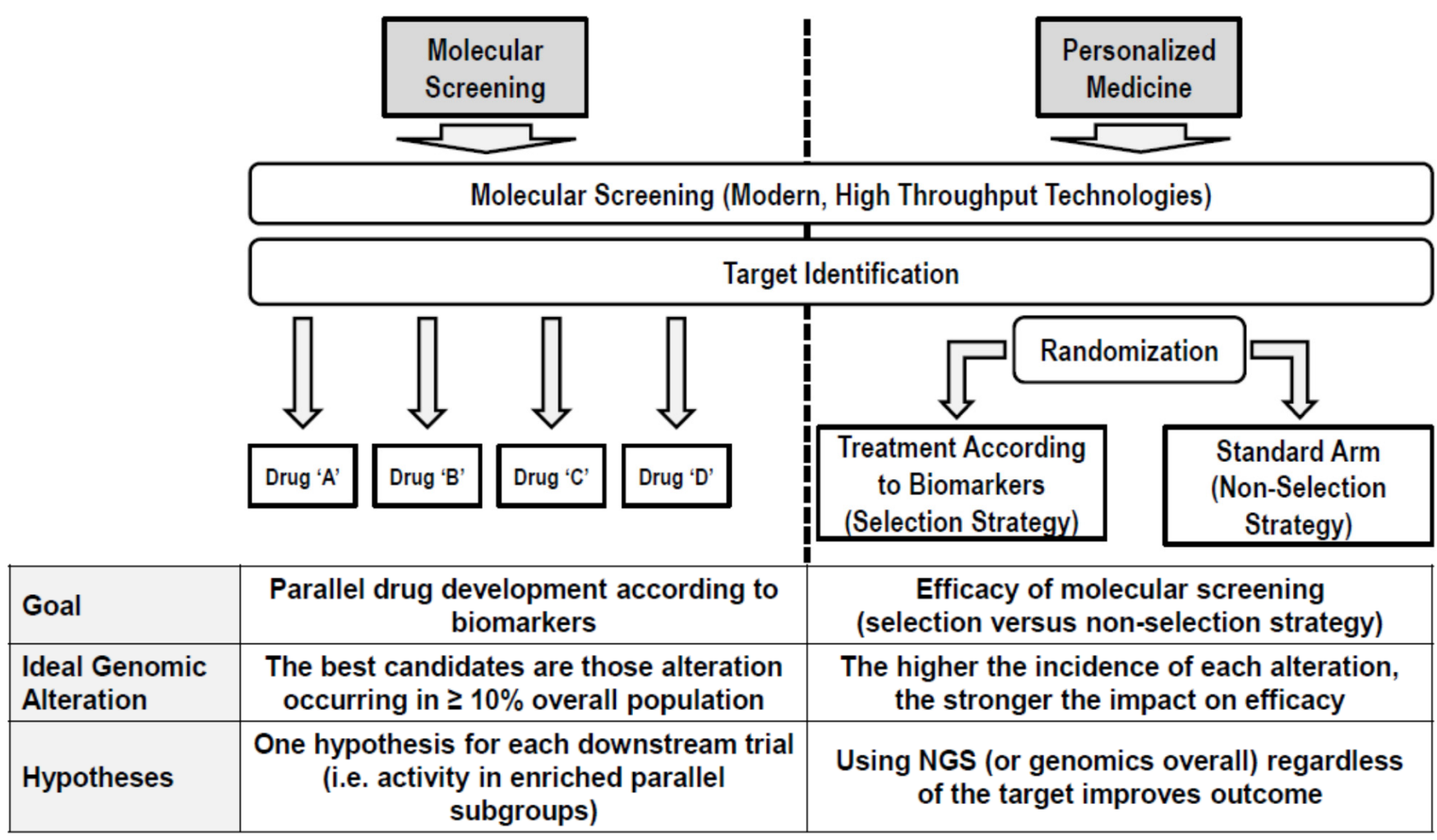

Figure 1. Efficiency of the "personalized model".

However, this new model of drug development has not only potentially reduced the time and costs required for the entire drug development (reducing the number of patients to be enrolled in clinical trials and discarding early unpromising drugs) but has radically changed the way early phase trials were designed.

Traditionally, the goals of phase 1 trials were to find, using toxicity as an endpoint, with the recommended dose and schedule of a new drug for phase 2 studies then used evaluate the antitumor activity. One cornerstone was that, usually, these trials had little or no therapeutic intended benefit (objective response rate $[\mathrm{ORR}] \leq 5 \%$ ) and patients to be considered were not selected for tumor histotype (all-comers). First experiences in matching the patients with molecular targeted drugs in phase 1 trials showed a dramatic increase in the average ORR registered in clinical trials [11,12] and fostered the debate over the therapeutic opportunity of phase 1 trials [13]. Therefore, even more frequently, modern phase 1 clinical trials are no longer enrolling all-comers for which no standard treatments are available but instead use very narrow selection criteria in order to maximise the possibility to catch a potential early activity. According to this changing strategy, a prominent role is held by a tumor biopsy before starting treatments and the screening phase, and during the trial participation and correlated biomarkers/pharmacodynamics endpoints.

In parallel, the sample size of phase 1 clinical trials is increasing over time. In particular, after the maximum tolerated dose (MTD) is established, in modern phase 1 trials patients are very often enrolled in dose expansion cohorts (DECs), in which the main goal is to determine the preliminary activity of the drug.

Interestingly, it has been reported that the use of DEC increased over time from $12 \%$ in 2006 to $38 \%$ in 2011, and that efficacy/activity is the main outcome of $33 \%$ of these [14]. Moreover, data from DEC identified a new toxic effect that was not described during the 
dose escalation in $54 \%$ of the trials and led to a recommended phase 2 dose (RP2D) in 13\% of them. More recently, based on similar data, it was reported that the use of DEC increased the possibility of success in phase 2 trials, but the size of the DEC (over 20 patients) is not correlated with this probability of success [15].

The sample size, primarily determined by the DEC size, is not a trivial point considering that, analogously, the sample size of phase 1 increased over time, and that this increase is correlated with the DEC use, with the ORR as endpoint, and is rarely justified by a proper statistical design [16].

Overall, all these new features related to the design, the conduction and the interpretation of early phase trials in oncology led to an unprecedented enthusiasm by a part of the scientific community claiming systematic approval after phase 1 [17]. On the other hand, the scientific community should carefully consider this trend of reducing drug development to the activity demonstration in DECs. Firstly, as we commented, a statistical hypothesis rarely reduces the sample size of those phase 1 trials, thus the results are mostly unreliable. Secondly, and perhaps most importantly, claiming the success of a drug based on unreliable and soft endpoints like ORR stops the development and impairs the possibility to demonstrate a meaningful benefit in terms of overall survival (OS) or progression-free survival (PFS), that requires even more time in case of, theoretically, highly efficient drugs. Under this perspective, an important role should also be played by regulatory agencies. In fact, a peculiar accelerated approval/breakthrough designation by the FDA permitted the approval of these drugs after phase 1, whilst other Regulatory Agencies (i.e., European Medicine Agency [EMA]) required more data from phase 2/3 trials. A concrete and joint effort in reviewing these approvals would certainly reduce the uncertainty in which these drugs are approved, the withdrawals often required due to additional data and the heterogeneity in the access to innovative drugs across the world.

\section{Examples of Drug Development Programs in NSCLC: The Case of Gefitinib, Crizotinib and Osimertinib for Oncogene-Addicted NSCLC}

Targeted therapy represents the pivotal treatment for oncogene-addicted NSCLC and its use in clinical practice is becoming wider [18]. While these innovative therapeutical options have improved the outcomes of a subgroup of patients affected by molecularlyaddicted NSCLC, the counterpart is that targeted therapy has different mechanisms of action, drug kinetics and dynamics, efficacy and toxicity profiles compared with standard chemotherapy [19]. Given these intrinsic differences, a drug development methodology requires novel approaches. All these aspects impair classical early clinical trial designs from being effective and efficient.

With the advent of targeted therapies, biomarkers have become increasingly relevant, influencing modern drug development and trial design. The most relevant aspect is related to a patient selection that can influence trials results from the earliest phases onwards. Indeed, the identification of biomarkers provides the possibility to use tumors and patient's characteristics to predict drug efficacy, guiding the treatment selection for each individual patient [20]. In particular, a validated predictive marker can prospectively identify individuals who are likely to have a positive clinical outcome, such as improved survival or decreased toxicity, from a specific treatment [21]. Moreover, targeted therapy has a toxicity profile significantly different from cytotoxic agents and typically results from target effects on normal tissues. As a result, targeted therapy has a toxicity profile that does not necessarily correlate with the MTD, historically the main endpoint of phase 1 chemotherapy trials is crucial in identifying the RP2D. Indeed, the correlation between toxicity and activity may be less linear than with conventional cytotoxic agents. In up to a third of phase 1 trials of molecularly targeted drugs, the MTD is not reached and therapeutic activity may be seen at the low-dose levels used in the early stages of clinical trials with targeted drugs [22]. Therefore, with the new molecular agents, the occurrence of more adverse events than the higher tolerated dose, should affect dose escalation and define the dose to be chosen in subsequent trial phases [23]. As a consequence, new 
trial designs and the corresponding endpoints need to be adapted to the specific agents being investigated.

Here, we report some examples of targeted drug development, showing how these programs have been affected by the timing of biomarker detection, the adverse events reported and, later, by the expertise about disease biology/heterogeneity acquired over time.

In recent years, phase 1 trials have enrolled more patients than those traditionally required for subsequent phase 2-3 trials. The rationale for such large phase 1 trials is based on the evaluation of activity endpoints in specific subsets of patient populations selected according to the presence of predictive biomarkers. This phenomenon blurs the lines between phase 1, 2 and 3 trials and allows accelerating drugs approval. One of the first drugs approved in this manner in thoracic oncology was crizotinib, a dual tyrosine-protein kinase MET and ALK inhibitor [24]. In 2006, the FIH phase 1 study with crizotinib started with a dose escalation (from $50 \mathrm{mg}$ once daily to $300 \mathrm{mg}$ twice daily) in 37 patients affected by advanced cancers. Dose-limiting fatigue in the cohort receiving $300 \mathrm{mg}$ twice daily led to establish the regimen of $250 \mathrm{mg}$ twice daily in a 28-day cycle as the RP2D. This part of the trial was followed by screening for ALK or MET aberrations in specific histotypes, identifying promising results in two patients with $A L K$-rearranged advanced NSCLC. For this reason, in 2008, the cohort of ALK-rearranged NSCLC patients was expanded. The ORR from 19 patients with pre-treated ALK-positive NSCLC was $53 \%$; these data were confirmed in 82 patients with an ORR of $57 \%$. The most frequent adverse events were grade 1-2 gastrointestinal events, visual alterations and transaminase increase. All toxicities reversed on cessation of crizotinib [25]. An expanded cohort of 149 patients was enrolled in the phase 1 PROFILE 1001 trial, in which crizotinib confirmed its activity, achieving an ORR of $60.8 \%$ and leading to rapid responses (median time to first documented response was 7.9 weeks) and durable (median duration of response was 49.1 weeks). The greatest proportions of responses were noted in the treatment of naïve patients, those with the lowest performance status score, and Asian patients. In this larger number of patients treated with crizotinib, mainly grade 1-2 side effects were reported and patients recovered after stopping crizotinib treatment $[26,27]$. The marked activity of crizotinib observed in the phase 1 study has led to phase 2-3 trials. The PROFILE 1005 is a phase 2, open-label single arm trial of efficacy and safety of crizotinib in advanced $A L K$-rearranged pre-treated NSCLC patients. Crizotinib confirmed a strong efficacy in $A L K$-rearranged NSCLC patients, showing an ORR of approximately $60 \%$, and a tolerable safety profile [28]. The crizotinib example highlights the fact that an extended expansion cohort allowed us to estimate activity endpoints, such as response, with more precision by enrolling more and more patients after only a handful of initial responses are observed, and showed that a strong candidate biomarker exists [29]. These studies led to a rapid regulatory approval of crizotinib in 2011 [30].

Gefitinib is a different example of a targeted drug development program. It was evaluated as a single agent in four phase 1 clinical trials. In the first one [31], gefitinib was administrated once daily for 14 consecutive days, followed by 14 days off treatment. Dose escalation started at $50 \mathrm{mg}$ and continued to $925 \mathrm{mg}$ or until a consistent dose-limiting toxicity (DLT) was reached. The most frequent adverse events were grade 1-2 rash, nausea and diarrhoea. Of 16 patients with NSCLC, 4 achieved partial response. In a second study, gefitinib was administrated from 150 to $1000 \mathrm{mg}$ /day for consecutive 28 days. At $1000 \mathrm{mg} /$ day, 5 out of 12 patients experienced DLT developing grade 3 diarrhoea. In this study, 19 patients had stable disease [32]. In the third study, 71 patients were enrolled and 39 had NSCLC. At doses $\geq 800 \mathrm{mg}, 45 \%$ of patients required dose reductions. One partial response and 6 prolonged stable disease responses were observed [33]. The fourth phase 1 study investigated the tolerability and toxicity of gefitinib in Japanese patients with solid tumors. Overall, 31 patients were included and received oral gefitinib on 14 consecutive days every 28 days. Dose escalation was from $50 \mathrm{mg} /$ day to a maximum of $925 \mathrm{mg} /$ day or DLT; 2 patients had DLT at $700 \mathrm{mg} /$ day. The adverse events were consistent with previous studies. Partial response was observed in 5/23 NSCLC patients [34]. Two randomized 
phase 2 clinical studies evaluated the safety and the activity of two doses of gefitinib (250 mg or $500 \mathrm{mg}$ ) in pre-treated NSCLC patients (IDEAL-1 and IDEAL-2). The IDEAL-1 [35] enrolled 210 patients who were pre-treated with one or two chemotherapy regimens, with at least one containing platinum. The IDEAL-2 study [36] included 221 patients who were pre-treated with two or more regimens containing platinum and docetaxel. In both studies, the two doses of gefitinib produced similar results in terms of ORR (approximately $20 \%$ in IDEAL-1 and 10\% in IDEAL-2), disease control rate (DCR, about 50\% in IDEAL-1 and $40 \%$ in IDEAL-2), and OS (about 8 months in IDEAL- 1 and 7 months in IDEAL-2). Overall, adverse events were more common in patients treated with $500 \mathrm{mg} /$ day. Based on these results, the dose chosen for gefitinib administration in NSCLC patients was $250 \mathrm{mg} /$ day. In these phase 2 studies, some efforts were made to identify predictive factors of response. In the IDEAL-1 trial, a multivariate analysis demonstrated that histology, female gender and performance status were associated with better outcomes, while in the IDEAL-2 trial, only the female gender showed results associated with a greater gefitinib efficacy. For these reasons, in 2004 the FDA accelerated gefitinib approval for advanced NSCLC after platinum-based and docetaxel treatments. Only the subsequent discovery of EGFR mutations led to several phase 2 trials in which a correlation between EGFR mutations and gefitinib efficacy was validated. For example, an ORR of $95 \%$ and $73.9 \%$ and a PFS of 8.9 and 9.1 months, respectively, were observed in 43 patients with exon 19 deletions and L858R mutations [37]. In the iTARGET trial [38] chemo-naïve patients with non-squamous NSCLC were selected based on clinical characteristics typically associated with EGFR mutations (non-smokers, adenocarcinoma histology, females, Asiatic patients). In this study, mutations were identified in 35\% of patients and the ORR was $78 \%$ and $59 \%$ for patients carrying L858R mutation and exon 19 deletion, respectively, whereas it was $0 \%$ in patients without these two alterations. Several other trials confirmed these results, showing that gefitinib efficacy was associated with the presence of EGFR mutations, regardless of ethnicity, gender, performance status or smoking history.

The development of gefitinib in NSCLC is a clear example of how difficult it was to conduct clinical trials with molecular-targeted agents when little was known about predictive factors and selection criteria. The key point in choosing a methodology of clinical research with target-based agents is the identification of those patients who are expected to benefit more. The preliminary identification of effective molecular targets in the early phases of drug development allows selecting only those patients who are more likely to respond to a specific targeted agent. Otherwise, the presence of an unrecognized molecular heterogeneity can lead to a falsely negative study that can fail to detect a truly effective new therapy, leading to the rejection of a potentially useful drug but in the context of a molecularly-selected population [39]. The gefitinib development program highlights the practical challenges in conducting biomarker research. The sooner a predictive biomarker is identified, the more focused and efficient the drug development program can become. The major problem in the gefitinib development was that the identification of the drug target progressed in parallel with its clinical development, extending the time for first-line drug approval. Ideally, biomarkers need to be identified in preclinical studies to enable a more efficient clinical development [40].

A third example of drug development program involves osimertinib. This drug was designed to inhibit EGFR in a covalent irreversible manner, harboring preferential activity against sensitizing and $T 790 \mathrm{M}$ resistance mutations, compared with the wildtype form of the receptor. Preclinically, osimertinib inhibits signaling pathways and cellular growth of EGFR mutant and T790M resistant cell lines in vitro [41]. In vivo, this translates into sustained tumor regression in EGFR-mutant tumor xenograft and transgenic single- and double-mutant models [41]. Osimertinib was clinically developed directly in EGFR-mutated NSCLC patients through the AURA series of trials. In the phase 1 AURA trial [42], the safety and efficacy of osimertinib was assessed in 253 EGFR-mutated metastatic NSCLC patients, who progressed while receiving first- or second-generation EGFR-TKIs. Building on the knowledge and learnings from clinical studies with gefitinib, 
the AURA study incorporated a biomarker-defined patient selection, which improved the chances of demonstrating clinical activity. The study comprised a dose-escalation cohort, with 31 patients, and a dose expansion cohort enrolling 222 patients who received oral osimertinib from 20 to $240 \mathrm{mg} /$ day. No DLT were observed, with an ORR of 51\%. In the expansion cohorts, tumor biopsies were required for central determination of EGFR T790M status with an ORR of $61 \%$ in 127 patients that obtained positive results. The median PFS was 8.2 months for all patients, while it was 9.6 and 2.8 months in EGFR T790M-positive and -negative patients, respectively. The dose of $80 \mathrm{mg}$ once daily was selected for further trials. The phase 1 AURA study also included two cohorts of treatmentnaïve patients [43]. A total of 30 patients received osimertinib at $80 \mathrm{mg} /$ day and 30 at $160 \mathrm{mg}$ /day. Overall ORR was $67 \%$ in the $80 \mathrm{mg}$ group, $87 \%$ in the $160 \mathrm{mg}$ group and $77 \%$ across doses. Median PFS was 22.1, 19.3 and 20.5 months, respectively. The results confirmed $80 \mathrm{mg}$ /day as the dose of osimertinib to investigate in the following first-line trial. In the AURA phase 2 extension cohort [44], 201 patients were enrolled with an ORR of $62 \%$. Median PFS was 12.3 months and the 1-year survival rate was $79 \%$. ORR and PFS were similar between the second- and third-line or more cohorts and by the common EGFR sensitizing mutation status. In the phase 2 AURA2 trial, 210 patients were enrolled and treated with $80 \mathrm{mg} /$ day of osimertinib [45], with an ORR of 70\%. Median PFS was 9.9 months and the 1-year survival rate was $81 \%$. In both trials, lung cancer symptoms, quality of life and physical functioning domains improved. The final selection of the dose to be used for commercialization, as well as phase 3 development, was made in February 2014, only 11 months after the first dose in humans. The development of osimertinib followed a biomarker-driven, adaptive approach that involved close collaboration between industry partners and global regulatory bodies, including the FDA and the European Medicines Agency (EMA). On 13 November 2015, osimertinib received FDA approval for patients whose tumors have a specific EGFR mutation (T790M) and whose disease has progressed after treatment with other EGFR-tyrosine kinase inhibitors (TKIs) therapy, following a clinical development period of just over 2.5 years from the first patient dosed to the first approval. This was made possible by multiple factors, the most relevant of which was the experience acquired during gefitinib development and the increasing expertise in the biology of EGFR-mutant NSCLC and in the chemistry of EGFR-TKIs [46]. This has been one of the fastest development journeys for a drug in history.

Based on these few historical examples, we have learned that when a targeted drug is administrated in a study population not selected by any biomarker, trials may produce negative results. However, the early detection of biomarker-driven biology helps to obtain a greater benefit for a selected population and can reduce the required time for drug approval (Table 1). Although toxicity remains the most commonly used phase 1 endpoint to RP2D, biomarker effects, pharmacokinetic and optimal biological doses (intended as the doses required to obtain the target inhibition and, consequently, the drug efficacy) need to be taken into account [20]. Ideally, phase 1 trials for target-based drugs should always be designed to determine whether the target can be inhibited in vivo at a tolerable dose and to estimate the dose or drug concentration required to achieve and maintain maximum inhibition of the target in vivo [47].

For all the above reasons, there is an urgent need to keep designing biomarker-driven early-phase oncology trials, addressing key questions that provide mechanistic insight into target modulation, drug sensitivity and resistance, as well as guiding decision making such as dose-escalation and schedule optimization [22]. 
Table 1. Differences in tyrosine kinase inhibitors development programs.

\begin{tabular}{cccc}
\hline Characteristics & Gefitinib & Crizotinib & Osimertinib \\
\hline $\begin{array}{c}\text { Year of phase 1 trials starting } \\
\begin{array}{c}\text { Time to biomarker identification } \\
\text { Year of drug approval for } \\
\text { targeted population }\end{array}\end{array}$ & $\begin{array}{c}2002 \\
\text { Phase 2 trials }\end{array}$ & 2006 & 2012 \\
Time required for drug approval & 2014 & Expansion cohort phase 1 trial & Pre-clinical phase \\
$\begin{array}{c}\text { Type of drug } \\
\text { development program }\end{array}$ & $\begin{array}{c}\text { Classic drug development } \\
\text { from phase 1 to phase 3 trials } \\
\text { (with late biomarker } \\
\text { identification) }\end{array}$ & $\begin{array}{c}\text { Phase 1 expansion cohort with } \\
\text { targeted population }\end{array}$ & $\begin{array}{c}\text { Classic drug development } \\
\text { from phase 1 to phase 3 } \\
\text { trials in the selected } \\
\text { population }\end{array}$ \\
\hline
\end{tabular}

\section{Examples of Drug Development Programs in NSCLC: The Case of Nivolumab, Pembrolizumab and Avelumab for Non-Oncogene Addicted NSCLC}

Immune checkpoint inhibitors (ICIs) have dramatically changed the therapeutical landscape of NSCLC, with immunotherapy, alone or in combination with chemotherapy, being the standard up-front approach for almost all the patients affected by non-oncogeneaddicted tumors [48]. However, several issues related to the conduction of clinical trials with ICIs are still unresolved. In particular, major challenges remain regarding the optimal methodology to conduct clinical trials focused on ICIs, dose finding, safety profile and the radiological assessment of response to these drugs.

Clinical trials involving ICIs, and in particular phase 1 trials, need to answer multiple questions within a short timeframe to accelerate the classical drug development process from early to regulatory phases. Interestingly, adaptive design trials, especially in the immunotherapy field, have revolutionized the classical paradigm of drug development based on phase 1, phase 2 and phase 3 steps. From adaptive design trials, we have learned that several questions could receive an answer at one time to speed up the process [49].

Drug development programs involving ICIs need to also consider the different pattern of toxicities, which can be peculiar and radically different from those observed during chemotherapy or targeted therapy. The conventional endpoints of phase 1 clinical trials represented by the classical dose escalation and the standard DLT assessment could not capture the late onset of immunotherapy-related toxicities [50]. In this context, early trials involving ICIs should include a longer DLT period for a better selection of the optimal phase 2 dose.

The major challenge in the immunotherapy early trials is represented by the identification of predictive biomarkers of efficacy/toxicity and the related assays method for their testing.

Several candidate biomarkers potentially able to identify patients who are more likely to benefit from ICIs, such as tumor mutational burden (TMB) [51,52], tumor-infiltrating lymphocytes [53] and circulating factors [54] have been investigated in the past few years [55].Nevertheless, among them only PD-L1 expression was demonstrated to be associated with an ICIs benefit $[56,57]$. In this light, partially similarly to the abovementioned scenario of oncogene-addicted tumors, the early study and identification of effective predictive biomarkers would allow a more effective drug development program, mainly focused on those specific populations more likely to achieve a benefit from ICIs.

Herein, we report three examples of immunological drug development, underlying caveats and peculiarities in early clinical steps.

The tolerability and activity of nivolumab, a fully human IgG4 PD-1 immune checkpoint inhibitor antibody, were firstly reported in patients with NSCLC, melanoma and renal cell carcinoma treated in a phase 1 multidose clinical trial [58], in which patients were not selected by PD-L1 expression. In 2015, the OS results in NSCLC patients treated with nivolumab were published, revealing encouraging survival rates and durable responses [59]. Nivolumab therapy was generally well tolerated, with only $14 \%$ of patients experiencing grade 3 to 4 treatment-related adverse events. Based on these results, phase 
3 clinical trials were conducted, using nivolumab at a dose of $3 \mathrm{mg} / \mathrm{kg}$ administered intravenously every 2 weeks based on pharmacokinetic exposure, safety and efficacy [59]. The results of CheckMate 017 and CheckMate 057 led to introduction of nivolumab in the treatment, respectively, of squamous and non-squamous pre-treated NSCLC [60,61]. An update of the phase 1 trials showed that 5 -year OS was 16\% for squamous and $15 \%$ for non-squamous patients [62], although the reported 9.9 months of median OS could not adequately capture the long benefit demonstrated by the plateaus in the tails of the survival curves.

In the phase 1 trial with nivolumab, tumor specimens from 42 patients were evaluated by the murine anti-human PD-L1 monoclonal antibody $5 \mathrm{H} 1$ and PD-L1 positivity was defined by $5 \%$ or more of tumor cells. None of the 17 patients with PD-L1 negative tumors had an ORR, while nine out of $25(35 \%)$ patients with PD-L1 positive tumors had a response ( $p=0.006$ ) [63]. A group evaluating immunohistochemical features from patients with colorectal carcinoma, renal cell carcinoma, NSCLC, melanoma or prostate cancer on the phase 1 nivolumab trial, including PD-1, PD-L1 and PD-L2 expression, patterns of immune cell infiltration and lymphocyte subpopulations, demonstrated that tumor PD-L1 expression correlated the most with ORR to anti-PD-1 therapy, based on assessing 41 pre-treatment tumor specimens [63].

In CheckMate 012, a multicohort phase 1 study in previously untreated patients with NSCLC, results from a cohort of 20 patients showed a good safety profile and durable responses [64]. Among the 10 patients with a PD-L1 expression level of 5\% or more, ORR was $50 \%$, PFS at 24 weeks was 70\% and median PFS was 10.6 months. Although an increasing PD-L1 expression level was associated with a greater benefit in the expanded cohort, clinical activity was also observed in patients with a low or negative PD-L1 expression. Based on these results, PFS among patients with stage IV or recurrent NSCLC with a PD-L1 expression level of $5 \%$ or more was chosen as the primary endpoint of the phase 3 CheckMate 026 trial, evaluating nivolumab versus chemotherapy alone as first line treatment [65]. However, this phase 3 trial failed to reach its primary endpoint. In fact, the median PFS was 4.2 months in nivolumab arm versus 5.9 months in chemotherapy arm (hazard ratio [HR] $1.15 ; 95 \%$ confidence interval [CI] $0.91-1.45 ; p=0.25$ ) in contrast with the KEYNOTE-024 positive results [66]. The application of different assays to assess PD-L1 tumor expression, the criteria related to previous radiotherapy and different patients' characteristics, could contribute to explaining this difference [67].

Differences in biomarker tests and in PD-L1 expression cut-off point, test 22C 3 with cut-off of $50 \%$ with pembrolizumab versus the test $28-8$ clone and cut-off of $5 \%$ with nivolumab, could contribute to the discordance in terms of results between CheckMate 026 and KEYNOTE-024. In fact, it was assumed that patients considered at high PD-L1 expression in the pembrolizumab trial could be significantly different from those considered "high" in the nivolumab one. An important difference between these trials is represented by the percentage of patients who received prior radiotherapy, which was very high in CheckMate 026 (37.6\%) while, in KEYNOTE-024, prior radiation therapy of >30 Gy within 6 months of the first dose of trial treatment was an exclusion criterion. Indeed, radiation treatment may play a potential immunosuppressive role, although not yet a fully clarified one, leading to a decreased activity of ICIs on irradiated areas [68]. Moreover, a higher percentage of never-smoker patients was included in the nivolumab trial than in the pembrolizumab trial ( $11 \%$ versus $3 \%)$. The never-smoker population has lower mutational loads, potentially leading to decreased response to ICIs [69].

The Nivolumab "saga" in its early development demonstrated how important the fine tuning on the best selection of patients, based on a strong biomarker hypothesis could be, in particular in the perspective of subsequent phase 2 and 3 trials.

Pembrolizumab represents an example of optimal co-development of a drug with its companion diagnostic for detecting PD-L1. Early clinical data suggested that tumors expressing PD-L1 could better respond to pembrolizumab and consequently, an assay for detecting PD-L1 was urgently needed [70]. The expansion cohort of the phase 1 trial 
KEYNOTE-001 demonstrated, in patients affected by locally advanced or metastatic PDL1-positive (defined as TPS $\geq 50 \%$ ) NSCLC, higher ORR ( $45 \%$ for PD-L1 $\geq 50 \%, 16.5 \%$ for PD-L1 1-49\% and $10.7 \%$ for PD-L1 < 1\%) with longer duration of response compared with historical data [71]. KEYNOTE-001 implies a biomarker-based enrichment design: the cut-off selection for PD-L1 positivity and its validation provided the rationale for phase 2 and 3 trials testing pembrolizumab in PD-L1 positive NSCLC patients (threshold 1\% for KEYNOTE-010 and 50\% for KEYNOTE-024). In KEYNOTE-001, the so-called prototype assay, to distinguish it from later versions of the assay for PD-L1, was used: PD-L1 positivity was defined as membranous staining in at least $1 \%$ of cells (neoplastic and intercalated mononuclear inflammatory cells) within tumor nests or a distinctive staining pattern caused by the infiltration of mononuclear inflammatory cells in the stroma that formed a banding pattern adjacent to tumor nests [70]. Four immunohistochemical PD-L1 scoring methods, based on the proportion of PD-L1-expressing tumor cells, were considered in NSCLC: the receiver operating characteristic (ROC) analysis demonstrated that all four scores were equally predictive [70-72]. Moreover, KEYNOTE-001 represents a good example of an adaptive design trial, which led to FDA approval of pembrolizumab in both NSCLC and melanoma in a short timeframe ( $<4$ years) [73] and was capable of generating a huge amount of data simultaneously, with multiple implementations throughout a series of amendments. The KEYNOTE-010 phase 2/3 trial demonstrated the benefit of pembrolizumab versus docetaxel in patients with previously treated NSCLC and TPS $\geq 1 \%$ tumors [74]. A planned post-hoc analysis from the KEYNOTE-010 study indicated that pembrolizumab continued to improve OS versus docetaxel, regardless of whether PD-L1 expression had been assessed in newly collected or archival tissue samples [75]. Moreover, pembrolizumab became the first immunotherapy approved in first-line setting of advanced NSCLC with PD-L1 TPS $\geq 50 \%$, based on KEYNOTE-024 results which demonstrated a longer PFS and OS compared with chemotherapy [76], demonstrating how far-sighted the bet was on PD-L1 TPS $\geq 50 \%$ since early drug development. The Blueprint PD-L1 immunohistochemistry (IHC) Assay Comparison Project, divided into two phases: the preliminary one and the real-world one, demonstrated that the 22C3, 28-8 and SP263 assays may be interchangeable for tumor cell PD-L1 expression, whereas the SP142 assay showed lower sensitivity in determining TPS on tumor cells [76,77]. True harmonization among different assays with different cut-offs provided by multiple companies appeared to not be completely possible [78]. Nowadays, the outstanding clinical benefit of pembrolizumab in the selected patient population might be overcoming the need for harmonization. The development program of pembrolizumab and concurrent identification of a strong companion diagnostic led to a rapid process of authorization, winning (at least for now) the run to the first-line setting.

Avelumab is a human Ig-G1 monoclonal antibody with a wild-type Fc region targeting PD-L1 that was approved for the treatment of metastatic Merkel cell carcinoma. In a phase 1a dose-escalation and dose-expansion, avelumab showed antitumor activity and durable response in a large cohort of advanced solid tumors [79]. In 2017, the results of the dose-expansion cohort of phase $1 \mathrm{~b}$ in patients with previously treated metastatic NSCLC were published, demonstrating an acceptable safety profile and a promising antitumor activity [80]. Notably, patients were not selected on the basis of PD-L1 expression. However, patients with PD-L1 positive tumor cells using the $1 \%$ cut-off had longer PFS with avelumab than patients with PD-L1 negative tumors, based on tumor classification using the novel antibody clone (73-10) [80]. The consequent phase 3 study, a JAVELIN Lung 200 trial, did not meet the primary endpoint of OS, despite the fact that clinical activity and safety were noted [81]. The authors explained the failure in achieving the primary endpoint of this trial, underlying the high-frequency of post-study use of ICIs, the higher proportion of randomly assigned patients who did not receive any study treatment in the docetaxel group than in the avelumab group ( $8 \%$ versus $1 \%)$, methods of biomarker assessment and patients' and drug characteristics. However, the pre-specified exploratory analyses showed that patients with higher PD-L1 expression had longer PFS and OS. Notably, the PD-L1 assay used in this 
trial (73-10 assay) has higher sensitivity to detect PDL-1 positivity than other assays (such as 22C3 for pembrolizumab and SP142 for atezolizumab) [82]. In the phase 1 expansion cohort of the JAVELIN solid tumor trial, avelumab monotherapy in first-line setting of advanced NSCLC demonstrated clinical activity and an acceptable safety profile [83]. Although around $28 \%$ of patients were not evaluable for tumor PD-L1 expression and the number of patients in PD-L1 subgroup is low ( $\mathrm{n}=38$ ), patients with $\geq 50 \%$ and $\geq 80 \%$ PD-L1-positive tumors showed ORRs of $22.6 \%$ and $26.3 \%$, respectively [79]. Based on these encouraging results, a phase III clinical trial (JAVELIN Lung 100 study) is currently ongoing, assessing first-line avelumab monotherapy compared with platinum-based doublet chemotherapy in patients with PD-L1-positive NSCLC (NCT02576574).

As we learned from these trials, early clinical development programs involving immunological agents have to take into account, beyond safety and activity, the optimal selection of patients, based on pre-specified biomarkers. To date, pembrolizumab, compared to other ICIs such as nivolumab and avelumab, represents an example of how crucial the identification of a strong biomarker hypothesis is from early phases. The codevelopment of a companion diagnostic together with a methodical approach to clinical development accelerated the approval process in pembrolizumab indications. In parallel with an optimal biomarker-based drug development, an adaptive design could be adopted to speed up the process from early to registrational/pivotal phases [49] (Table 2).

Table 2. Differences in immune checkpoint inhibitors development programs.

\begin{tabular}{|c|c|c|c|}
\hline Characteristics & Nivolumab & Pembrolizumab & Avelumab \\
\hline Year of phase 1 trials starting & 2009 & 2012 & 2013 \\
\hline $\begin{array}{l}\text { Co-development of } \\
\text { companion diagnostic from } \\
\text { early phases }\end{array}$ & $\mathrm{NO}$ & YES & $\mathrm{NO}$ \\
\hline $\begin{array}{c}\text { Time required for FDA } \\
\text { drug approval }\end{array}$ & $\begin{array}{l}5 \text { years (approval in } \\
\text { second line) }\end{array}$ & $\begin{array}{l}3 \text { years (approval in } \\
\text { second line) * }\end{array}$ & Not approved \\
\hline $\begin{array}{c}\text { Type of drug } \\
\text { development program }\end{array}$ & $\begin{array}{l}\text { Classic drug development } \\
\text { from phase } 1 \text { to phase } 3 \text { trials }\end{array}$ & $\begin{array}{l}\text { Classic drug development } \\
\text { from phase } 1 \text { to phase } 3 \text { trials } \\
\text { (including adaptive } \\
\text { design trials) }\end{array}$ & $\begin{array}{l}\text { Classic drug development } \\
\text { from phase } 1 \text { to phase } 3 \text { trials }\end{array}$ \\
\hline
\end{tabular}

* Only in tumors with expression of programmed death ligand-1 (PD-L1) tumor proportion score (TPS) $\geq 1 \%$; FDA: Food and Drug Administration.

\section{Conclusions}

New challenges and considerations affect the conduct and feasibility of trials in oncology research and specifically in metastatic NSCLC. We are going from an empirical approach, including large trials comparing treatments, to a tailored approach in which the trials are designed to ask biologically relevant questions. In this deep changing of clinical research, to reach a successful conversion, the methodology of the research and infrastructure should be extremely restructured in order to better understand the biology of the disease, the mechanism of action of new agents, the new methodological approaches to apply and prediction of toxicity or activity. The examples of drug development programs in oncogene- and non-oncogene-addicted NSCLC that we reported highlight how these large shifts in the standard paradigm of cancer clinical research can impact the real-world practice. In the future, concepts such as phase 1 expansion cohorts replacing phase 2 studies, regulatory approvals based on nonrandomized trials and tumor agnostic approvals will be firmly adopted in the field of drug development. The FDA has already shown its will to approve agents that were evaluated in only a small number of patients, even based on single-arm trials, as traditionally large registration trials may never be feasible or ethically appropriate within some NSCLC subtypes [8]. A further novel approach by FDA was the request of a post-approval study testing a lower dose of sotorasib, a Kirsten rat sarcoma (KRAS) G12C-mutated inhibitor. Thus, this request highlights how the dose finding process that was usually part of phase 1 trials can also be performed even post marketing. In fact, 
a multicenter randomized clinical trial to compare the safety and efficacy of sotorasib at $960 \mathrm{mg}$ once daily vs. a lower daily dose of $240 \mathrm{mg}$ in patients with advanced NSCLC is ongoing [84].

The continuing development of the next-generation sequencing tool will increase the use of assignment of patients to matched treatments according to multiple driving mutations, biomarkers, or pathways [85]. This concept of personalized medicine will lead to reducing the potential use of drugs in non-responders. However, it may increase diagnostic budgets by requiring the testing of a whole patient population to select the groups of eligible patients who might benefit, leading to a potential higher cost.

Overall, the identification of predictive biomarkers is one of the greatest challenges of NSCLC research that should be optimized with solid methodological trial designs to maximize the clinical outcomes.

Funding: This research received no external funding.

Data Availability Statement: Not applicable.

Acknowledgments: E.B. is supported by Institutional funds of Università Cattolica del Sacro Cuore (UCSC-project D1-2019-2020). E.B. is currently supported by the Associazione Italiana per la Ricerca sul Cancro (AIRC) under Investigator Grant (IG) No. IG20583.

Conflicts of Interest: A.R. declares advisory boards and honoraria as speaker's bureau from MSD, Eli Lilly, AstraZeneca, Roche, Boehringer Ingelheim. S.P. received honoraria or speaker's fees from Astra-Zeneca, BMS, Boehringer Ingelheim, MSD, Roche and Istituto Gentili. L.C. received advisory board fees from Pfizer and Novartis. G.D. has served on the advisory board of Beigene and received support for travel and accommodation from Roche. E.B. received speaker's and travel fees from MSD, Astra-Zeneca, Celgene, Pfizer, Helsinn, Eli-Lilly, BMS, Novartis and Roche. E.B received consultant fees from Roche, Pfizer. E.B. received institutional research grants from Astra-Zeneca and Roche. All other authors declare they have no conflicts of interest to disclose.

\section{References}

1. Arrowsmith, J.; Miller, P. Trial watch: Phase II and phase III attrition rates 2011-2012. Nat. Rev. Drug Discov. 2013, 12, 569. [CrossRef] [PubMed]

2. Amiri-Kordestani, L.; Fojo, T. Why do phase III clinical trials in oncology fail so often? J. Natl. Cancer Inst. 2012, 104, 568-569. [CrossRef] [PubMed]

3. Gan, H.K.; You, B.; Pond, G.R.; Chen, E.X. Assumptions of expected benefits in randomized phase III trials evaluating systemic treatments for cancer. J. Natl. Cancer Inst. 2012, 104, 590-598. [CrossRef] [PubMed]

4. Munoz, J.; Swanton, C.; Kurzrock, R. Molecular profiling and the reclassification of cancer: Divide and conquer. Am. Soc. Clin. Oncol. Educ. Book 2013, 33, 127-134. [CrossRef] [PubMed]

5. Gerlinger, M.; Rowan, A.J.; Horswell, S.; Math, M.; Larkin, J.; Endesfelder, D.; Gronroos, E.; Martinez, P.; Matthews, N.; Stewart, A.; et al. Intratumor heterogeneity and branched evolution revealed by multiregion sequencing. N. Engl. J. Med. 2012, 366, 883-892. [CrossRef] [PubMed]

6. Rossi, A. Immunotherapy and NSCLC: The long and winding road. Cancers 2020, 12, 2512. [CrossRef]

7. Planchard, D.; Popat, S.; Kerr, K.; Novello, S.; Smit, E.F.; Faivre-Finn, C.; Mok, T.S.; Reck, M.; Van Schil, P.E.; Hellmann, M.D.; et al. Metastatic Non-Small Cell Lung Cancer: ESMO Clinical Practice Guidelines for Diagnosis, Treatment and Follow-up. Available online: https:/ / www.esmo.org/guidelines/lung-and-chest-tumours/clinical-practice-living-guidelines-metastaticnon-small-cell-lung-cancer (accessed on 2 April 2021).

8. Drilon, A. TRK inhibitors in TRK fusion-positive cancers. Ann. Oncol. 2019, 30 (Suppl. S8), viii23-viii30. [CrossRef]

9. Jardim, D.L.; Schwaederle, M.; Hong, D.S. An appraisal of drug development timelines in the era of precision oncology. Oncotarget 2016, 7, 53037-53046. [CrossRef]

10. Mandrekar, S.J.; Dahlberg, S.E.; Simon, R. Improving clinical trial efficiency: Thinking outside the box. Am. Soc. Clin. Oncol. Educ. Book 2015, 35, e141-e147. [CrossRef]

11. Tsimberidou, A.M.; Iskander, N.G.; Hong, D.S. Personalized medicine in a phase I clinical trials program: The MD Anderson Cancer Center initiative. Clin. Cancer Res. 2012, 18, 6373-6383. [CrossRef]

12. Schwaederle, M.; Zhao, M.; Lee, J.J. Association of biomarker-based treatment strategies with response rates and progression-free survival in refractory malignant neoplasms: A meta-analysis. JAMA Oncol. 2016, 2, 1452-1459. [CrossRef]

13. Adashek, J.J.; LoRusso, P.M.; Hong, D.S. Phase I trials as valid therapeutic options for patients with cancer. Nat. Rev. Clin. Oncol. 2019, 16, 773-778. [CrossRef] 
14. Manji, A.; Brana, I.; Amir, E. Evolution of clinical trial design in early drug development: Systematic review of expansion cohort use in single-agent phase I cancer trials. J. Clin. Oncol. 2013, 31, 4260-4267. [CrossRef]

15. Bugano, D.D.; Hess, K.; Jardim, D.L. Use of expansion cohorts in phase I trials and probability of success in phase II for 381 anticancer drugs. Clin. Cancer Res. 2017, 23, 4020-4026. [CrossRef]

16. Dahlberg, S.E.; Shapiro, G.I.; Clark, J.W. Evaluation of statistical designs in phase I expansion cohorts: The Dana-Farber/Harvard Cancer Center experience. J. Natl. Cancer Inst. 2014, 106, dju163. [CrossRef]

17. Chabner, B.A. Early accelerated approval for highly targeted cancer drugs. N. Engl. J. Med. 2011, 364, 1087-1089. [CrossRef]

18. Ferrara, M.G.; Di Noia, V.; D’Argento, E.; Vita, E.; Damiano, P.; Cannella, A.; Ribelli, M.; Pilotto, S.; Milella, M.; Tortora, G.; et al. Oncogene-addicted non-small-cell lung cancer: Treatment opportunities and future perspectives. Cancers 2020, 12, 1196. [CrossRef]

19. Eisenhauer, E.A.; O’Dwyer, P.J.; Christian, M. Phase I clinical trial design in cancer drug development. J. Clin. Oncol. 2000, 18, 684-692. [CrossRef]

20. Booth, C.M.; Calvert, A.H.; Giaccone, G.; Lobbezoo, M.W.; Seymour, L.K.; Eisenhauer, E.A. End points and other considerations in Phase I studies of targeted anticancer therapy: Recommendations from the task force on Methodology for the Development of Innovative Cancer Therapies (MDICT). Eur. J. Cancer 2008, 44, 19-24. [CrossRef]

21. Mansinho, A.; Boni, V.; Miguel, M.; Calvo, E. New designs in early clinical drug development. Ann. Oncol. 2019, 30, 1460-1465. [CrossRef]

22. Tan, D.S.; Thomas, G.V.; Garret, M.D.; Banerji, U.; de Bono, J.S.; Kaye, S.B.; Workman, P. Biomarker-driven early clinical trials in oncology: A paradigm shift in drug development. Cancer J. 2009, 15, 406-420. [CrossRef]

23. Banerji, U.; Workman, P. Critical parameters in targeted drug development: The pharmacological audit trail. Semin. Oncol. 2016, 43, 436-445. [CrossRef]

24. Zou, H.Y.; Li, Q.; Lee, J.H.; McDonnell, S.R.; Yamazaki, S.; Koudriakova, T.B.; Alton, G.; Cui, J.J.; Kung, P.P.; Nambu, M.D.; et al. An orally available small-molecule inhibitor of c-Met, PF-2341066, exhibits cytoreductive antitumor efficacy through antiproliferative and antiangiogenic mechanisms. Cancer Res. 2007, 67, 4408-4417. [CrossRef]

25. Clark, J.W.; Camidge, D.R.; Kwak, E.L.; Maki, R.G.; Shapiro, G.I.; Chen, I.; Tan, W.; Randolph, S.; Christensen, J.G.; Ozeck, M.; et al. Dose-escalation trial of the ALK, MET \& ROS1 inhibitor, crizotinib, in patients with advanced cancer. Future Oncol. 2020, 16, 4289-4301. [PubMed]

26. Kwak, E.L.; Bang, Y.J.; Camidge, D.R.; Shaw, A.T.; Solomon, B.; Maki, R.G.; Ou, S.H.; Dezube, B.J.; Jänne, P.A.; Costa, D.B.; et al. Anaplastic lymphoma kinase inhibition in non-small-cell lung cancer. N. Engl. J. Med. 2010, 363, 1693-1703. [CrossRef] [PubMed]

27. Camidge, D.R.; Bang, Y.J.; Kwak, E.L.; Iafrate, A.J.; Varella-Garcia, M.; Fox, S.B.; Riely, G.J.; Solomon, B.; Ou, S.H.; Kim, D.W.; et al. Activity and safety of crizotinib in patients with ALK-positive non-small-cell lung cancer: Updated results from a phase 1 study. Lancet Oncol. 2012, 13, 1011-1019. [CrossRef]

28. Blackhall, F.; Camidge, D.R.; Shaw, A.T.; Soria, J.C.; Solomon, B.J.; Mok, T.; Hirsh, V.; Jänne, P.A.; Shi, Y.; Yang, P.C.; et al. Final results of the large-scale multinational trial PROFILE 1005: Efficacy and safety of crizotinib in previously treated patients with advanced/metastatic ALK-positive non-small-cell lung cancer. ESMO Open 2017, 2, e000219. [CrossRef] [PubMed]

29. Le-Rademacher, J.; Dahlberg, S.; Lee, J.; Adjei, A.A.; Mandrekar, S.J. Biomarker clinical trials in lung cancer: Design, logistics, challenges, and practical considerations. J. Thorac. Oncol. 2018, 13, 1625-1637. [CrossRef]

30. Blackhall, F.; Cappuzzo, F. Crizotinib: From discovery to accelerated development to front-line treatment. Ann. Oncol. 2018, 29, 1073. [CrossRef]

31. Ranson, M.; Hammond, L.A.; Ferry, D.; Kris, M.; Tullo, A.; Murray, P.I.; Miller, V.; Averbuch, S.; Ochs, J.; Morris, C.; et al. ZD1839, a selective oral epidermal growth factor receptor-tyrosine kinase inhibitor, is well tolerated and active in patients with solid, malignant tumors: Results of a phase I trial. J. Clin. Oncol. 2002, 20, 2240-2250. [CrossRef]

32. Baselga, J.; Rischin, D.; Ranson, M.; Calvert, H.; Raymond, E.; Kieback, D.G.; Kaye, S.B.; Gianni, L.; Harris, A.; Bjork, T.; et al. Phase I safety, pharmacokinetic, and pharmacodynamic trial of ZD1839, a selective oral epidermal growth factor receptor tyrosine kinase inhibitor, in patients with five selected solid tumor types. J. Clin. Oncol. 2002, 20, 4292-4302. [CrossRef]

33. Herbst, R.S.; Maddox, A.M.; Rothenberg, M.L.; Small, E.J.; Rubin, E.H.; Baselga, J.; Rojo, F.; Hong, W.K.; Swaisland, H.; Averbuch, S.D.; et al. Selective oral epidermal growth factor receptor tyrosine kinase inhibitor ZD1839 is generally well-tolerated and has activity in non-small-cell lung cancer and other solid tumors: Results of a phase I trial. J. Clin. Oncol. 2002, 20, 3815-3825. [CrossRef]

34. Nakagawa, K.; Tamura, T.; Negoro, S.; Kudoh, S.; Yamamoto, N.; Yamamoto, N.; Takeda, K.; Swaisland, H.; Nakatani, I.; Hirose, M.; et al. Phase I pharmacokinetic trial of the selective oral epidermal growth factor receptor tyrosine kinase inhibitor gefitinib ('Iressa', ZD1839) in Japanese patients with solid malignant tumors. Ann. Oncol. 2003, 14, 922-930. [CrossRef]

35. Fukuoka, M.; Yano, S.; Giaccone, G.; Tamura, T.; Nakagawa, K.; Douillard, J.Y.; Nishiwaki, Y.; Vansteenkiste, J.; Kudoh, S.; Rischin, D.; et al. Multi-institutional randomized phase II trial of gefitinib for previously treated patients with advanced non-small-cell lung cancer (The IDEAL 1 Trial). J. Clin. Oncol. 2003, 21, 2237-2246. [CrossRef]

36. Kris, M.G.; Natale, R.B.; Herbst, R.S.; Lynch, T.J., Jr.; Prager, D.; Belani, C.P.; Schiller, J.H.; Kelly, K.; Spiridonidis, H.; Sandler, A.; et al. Efficacy of gefitinib, an inhibitor of the epidermal growth factor receptor tyrosine kinase, in symptomatic patients with non-small cell lung cancer: A randomized trial. JAMA 2003, 290, 2149-2158. [CrossRef] 
37. Yang, C.H.; Yu, C.J.; Shih, J.Y.; Chang, Y.C.; Hu, F.C.; Tsai, M.C.; Chen, K.Y.; Lin, Z.Z.; Huang, C.J.; Shun, C.T.; et al. Specific EGFR mutations predict treatment outcome of stage IIIB/IV patients with chemotherapy-naive non-small-cell lung cancer receiving first-line gefitinib monotherapy. J. Clin. Oncol. 2008, 26, 2745-2753. [CrossRef]

38. Sequist, L.V.; Martins, R.G.; Spigel, D.; Grunberg, S.M.; Spira, A.; Jänne, P.A.; Joshi, V.A.; McCollum, D.; Evans, T.L.; Muzikansky, A.; et al. First-line gefitinib in patients with advanced non-small-cell lung cancer harboring somatic EGFR mutations. J. Clin. Oncol. 2008, 26, 2442-2449. [CrossRef]

39. Costanzo, R.; Piccirillo, M.C.; Sandomenico, C.; Carillio, G.; Montanino, A.; Daniele, G.; Giordano, P.; Bryce, J.; De Feo, G.; Di Maio, M.; et al. Gefitinib in non small cell lung cancer. J. Biomed. Biotechnol. 2011, 2011, 815269. [CrossRef]

40. Armour, A.A.; Watkins, C.L. The challenge of targeting EGFR: Experience with gefitinib in nonsmall cell lung cancer. Eur. Respir. Rev. 2010, 117, 186-196. [CrossRef]

41. Cross, D.A.; Ashton, S.E.; Ghiorghiu, S.; Eberlein, C.; Nebhan, C.A.; Spitzler, P.J.; Orme, J.P.; Finlay, M.R.; Ward, R.A.; Mellor, M.J.; et al. AZD9291, an irreversible EGFR TKI, overcomes T790M-mediated resistance to EGFR inhibitors in lung cancer. Cancer Discov. 2014, 4, 1046-1061. [CrossRef]

42. Janne, P.A.; Yang, J.C.-H.; Kim, D.W.; Planchard, D.; Ohe, Y.; Ramalingam, S.S.; Ahn, M.J.; Kim, S.W.; Su, W.C.; Horn, L.; et al. AZD9291 in EGFR inhibitor-resistant non-small cell lung cancer. N. Engl. J. Med. 2015, 372, 1689-1699. [CrossRef]

43. Ramalingam, S.S.; Yang, J.C.-H.; Lee, C.K.; Kurata, T.; Kim, D.W.; John, T.; Nogami, N.; Ohe, Y.; Mann, H.; Rukazenkov, Y.; et al. Osimertinib as first-line treatment of EGFR mutation-positive advanced non-small-cell lung cancer. J. Clin. Oncol. 2018, 36, 841-849. [CrossRef]

44. Yang, J.C.; Ahn, M.J.; Kim, D.W.; Ramalingam, S.S.; Sequist, L.V.; Su, W.C.; Kim, S.W.; Kim, J.H.; Planchard, D.; Felip, E.; et al. Osimertinib in pretreated T790M-positive advanced non-small-cell lung cancer: AURA study phase II extension component. J. Clin. Oncol. 2017, 35, 1288-1296. [CrossRef]

45. Goss, G.; Tsai, C.M.; Shepherd, F.A.; Bazhenova, L.; Lee, J.S.; Chang, G.C.; Crino, L.; Satouchi, M.; Chu, Q.; Hida, T.; et al. Osimertinib for pretreated EGFR Thr790Met positive advanced non-small-cell lung cancer (AURA2): A multicentre, open-label, single-arm, phase 2 study. Lancet Oncol. 2016, 17, 1643-1652. [CrossRef]

46. Yver, A. Osimertinib (AZD9291) - A science-driven, collaborative approach to rapid drug design and development. Ann. Oncol. 2016, 27, 1165-1170. [CrossRef]

47. Fox, E.; Curt, G.A.; Balis, F.M. Clinical trial design for target-based therapy. Oncologist 2002, 7, 401-409. [CrossRef]

48. Russo, A.; McCusker, M.G.; Scilla, K.A.; Arensmeyer, K.E.; Mehra, R.; Adamo, V.; Rolfo, C. Immunotherapy in lung cancer: From a minor god to the olympus. Adv. Exp. Med. Biol. 2020, 1244, 69-92.

49. Menis, J.; Hasan, B.; Besse, B. New clinical research strategies in thoracic oncology: Clinical trial design, adaptive, basket and umbrella trials, new end-points and new evaluations of response. Eur. Respir. Rev. 2014, 23, 367-378. [CrossRef]

50. Haanen, J.B.A.G.; Carbonnel, F.; Robert, C.; Kerr, K.M.; Peters, S.; Larkin, J.; Jordan, K. Management of toxicities from immunotherapy: ESMO Clinical Practice Guidelines for diagnosis, treatment and follow-up. Ann. Oncol. 2017, 28 (Suppl. S4), iv119-iv142. [CrossRef]

51. Snyder, A.; Wolchok, J.D.; Chan, T.A. Genetic basis for clinical response to CTLA-4 blockade. N. Engl. J. Med. 2015, $372,783$. [CrossRef]

52. Wang, Z.; Duan, J.; Cai, S.; Han, M.; Dong, H.; Zhao, J.; Zhu, B.; Wang, S.; Zhuo, M.; Sun, J.; et al. Assessment of blood tumor mutational burden as a potential biomarker for immunotherapy in patients with non-small cell lung cancer with use of a next generation sequencing cancer gene panel. JAMA Oncol. 2019, 5, 696-702. [CrossRef] [PubMed]

53. Tumeh, P.C.; Harview, C.L.; Yearley, J.H.; Shintaku, I.P.; Taylor, E.J.; Robert, L.; Chmielowski, B.; Spasic, M.; Henry, G.; Ciobanu, V.; et al. PD-1 blockade induces responses by inhibiting adaptive immune resistance. Nature 2014, 515, 568-571. [CrossRef] [PubMed]

54. Duchemann, B.; Remon, J.; Naigeon, M.; Mezquita, L.; Ferrara, R.; Cassard, L.; Jouniaux, J.M.; Boselli, L.; Grivel, J.; Auclin, E.; et al. Integrating circulating biomarkers in the immune checkpoint inhibitor treatment in lung cancer. Cancers 2020, $12,3625$. [CrossRef] [PubMed]

55. Nishino, M.; Ramaiya, N.H.; Hatabu, H.; Hodi, F.S. Monitoring immune-checkpoint blockade: Response evaluation and biomarker development. Nat. Rev. Clin. Oncol. 2017, 14, 655-668. [CrossRef] [PubMed]

56. Carbognin, L.; Pilotto, S.; Milella, M.; Vaccaro, V.; Brunelli, M.; Caliò, A.; Cuppone, F.; Sperduti, I.; Giannarelli, D.; Chilosi, M.; et al. Differential activity of nivolumab, pembrolizumab and MPDL3280A according to the tumor expression of programmed death-ligand-1 (PD L1): Sensitivity analysis of trials in melanoma, lung and genitourinary cancers. PLoS ONE 2015, 10, e0130142. [CrossRef]

57. Aguiar, P.N.; Santoro, I.L.; Tadokoro, H.; de Lima Lopes, G.; Filardi, B.A.; Oliveira, P.; Mountzios, G.; de Mello, R.A. The role of PD-L1 expression as a predictive biomarker in advanced non-small-cell lung cancer: A network meta-analysis. Immunotherapy 2016, 8, 479-488. [CrossRef]

58. Topalian, S.L.; Hodi, F.S.; Brahmer, J.R.; Gettinger, S.N.; Smith, D.C.; McDermott, D.F.; Powderly, J.D.; Carvajal, R.D.; Sosman, J.A.; Atkins, M.B.; et al. Safety, activity, and immune correlates of anti-PD-1 antibody in cancer. N. Engl. J. Med. 2012, 366, $2443-2454$. [CrossRef] 
59. Gettinger, S.N.; Horn, L.; Gandhi, L.; Spigel, D.R.; Antonia, S.J.; Rizvi, N.A.; Powderly, J.D.; Heist, R.S.; Carvajal, R.D.; Jackman, D.M.; et al. Overall survival and long-term safety of nivolumab (anti-programmed death 1 antibody, BMS-936558, ONO-4538) in patients with previously treated advanced non-small-cell lung cancer. J. Clin. Oncol. 2015, 33, 2004-2012. [CrossRef]

60. Brahmer, J.; Reckamp, K.L.; Baas, P.; Crinò, L.; Eberhardt, W.E.; Poddubskaya, E.; Antonia, S.; Pluzanski, A.; Vokes, E.E.; Holgado, E.; et al. Nivolumab versus docetaxel in advanced squamous-cell non-small-cell lung cancer. N. Engl. J. Med. 2015, 373, 123-135. [CrossRef]

61. Borghaei, H.; Paz-Ares, L.; Horn, L.; Spigel, D.R.; Steins, M.; Ready, N.E.; Chow, L.Q.; Vokes, E.E.; Felip, E.; Holgado, E.; et al. Nivolumab versus docetaxel in advanced nonsquamous non-small-cell lung cancer. N. Engl. J. Med. 2015, 373, 1627-1639. [CrossRef]

62. Gettinger, S.; Horn, L.; Jackman, D.; Spigel, D.; Antonia, S.; Hellmann, M.; Powderly, J.; Heist, R.; Sequist, L.V.; Smith, D.C.; et al. Five-year follow-up of nivolumab in previously treated advanced non-small-cell lung cancer: Results from the CA209-003 study. J. Clin. Oncol. 2018, 36, 1765-1784. [CrossRef]

63. Taube, J.M.; Klein, A.; Brahmer, J.R.; Xu, H.; Pan, X.; Kim, J.H.; Chen, L.; Pardoll, D.M.; Topalian, S.L.; Anders, R.A. Association of PD-1, PD-1 ligands, and other features of the tumor immune microenvironment with response to anti-PD-1 therapy. Clin. Cancer Res. 2014, 20, 5064-5074. [CrossRef]

64. Gettinger, S.; Rizvi, N.A.; Chow, L.Q.; Borghaei, H.; Brahmer, J.; Ready, N.; Gerber, D.E.; Shepherd, F.A.; Antonia, S.; Goldman, J.W.; et al. Nivolumab monotherapy for first-line treatment of advanced non-small-cell lung cancer. J. Clin. Oncol. 2016, 34, 2980-2987. [CrossRef]

65. Carbone, D.P.; Reck, M.; Paz-Ares, L.; Creelan, B.; Horn, L.; Steins, M.; Felip, E.; van den Heuvel, M.M.; Ciuleanu, T.E.; Badin, F.; et al. First-line nivolumab in stage IV or recurrent non-small-cell lung cancer. N. Engl. J. Med. 2017, 376, 2415-2426. [CrossRef]

66. Reck, M.; Rodriguez-Abreu, D.; Robinson, A.G.; Hui, R.; Csőszi, T.; Fülöp, A.; Gottfried, M.; Peled, N.; Tafreshi, A.; Cuffe, S.; et al. Pembrolizumab versus chemotherapy for PD-L1-positive non-small-cell lung cancer. N. Engl. J. Med. 2016, 375, 1823-1833. [CrossRef]

67. Remon, J.; Besse, B.; Soria, J.C. Successes and failures: What did we learn from recent first-line treatment immunotherapy trials in non-small cell lung cancer? BMC Med. 2017, 15, 55.

68. Leroi, N.; Lallemand, F.; Coucke, P.; Noel, A.; Martinive, P. Impacts of ionizing radiation on the different compartments of the tumor microenvironment. Front. Pharmacol. 2016, 7, 78. [CrossRef]

69. Rizvi, N.A.; Hellmann, M.D.; Snyder, A.; Kvistborg, P.; Makarov, V.; Havel, J.J.; Lee, W.; Yuan, J.; Wong, P.; Ho, T.S.; et al. Cancer immunology. Mutational landscape determines sensitivity to PD-1 blockade in non-small cell lung cancer. Science 2015, 348, 124-128. [CrossRef]

70. Dolled-Filhart, M.; Roach, C.; Toland, G.; Stanforth, D.; Jansson, M.; Lubiniecki, G.M.; Ponto, G.; Emancipator, K. Development of a companion diagnostic for pembrolizumab in non-small cell lung cancer using immunohistochemistry for programmed death ligand-1. Arch. Pathol. Lab. Med. 2016, 140, 1243-1249. [CrossRef]

71. Garon, E.B.; Rizvi, N.A.; Hui, R.; Leighl, N.; Balmanoukian, A.S.; Eder, J.P.; Patnaik, A.; Aggarwal, C.; Gubens, M.; Horn, L.; et al. Pembrolizumab for the treatment of non-small-cell lung cancer. N. Engl. J. Med. 2015, 372, 2018-2028. [CrossRef]

72. European Medicines Agency. Concept Paper on Predictive Biomarker-Based Assay Development in the Context of Drug Development and Lifecycle; European Medicines Agency: London, UK, 2017.

73. Kang, S.P.; Gergich, K.; Lubiniecki, G.M.; de Alwis, D.P.; Chen, C.; Tice, M.A.B.; Rubin, E.H. Pembrolizumab KEYNOTE-001: An adaptive study leading to accelerated approval for two indications and a companion diagnostic. Ann. Oncol. 2017, 28, 1388-1398. [CrossRef]

74. Herbst, R.S.; Baas, P.; Kim, D.W.; Felip, E.; Pérez-Gracia, J.L.; Han, J.Y.; Molina, J.; Kim, J.H.; Arvis, C.D.; Ahn, M.J.; et al. Pembrolizumab versus docetaxel for previously treated, PD-L1-positive, advanced non-small-cell lung cancer (KEYNOTE-010): A randomised controlled trial. Lancet 2016, 387, 1540-1550. [CrossRef]

75. Herbst, R.S.; Baas, P.; Perez-Gracia, J.L.; Felip, E.; Kim, D.W.; Han, J.Y.; Molina, J.R.; Kim, J.H.; Dubos Arvis, C.; Ahn, M.J.; et al. Use of archival versus newly collected tumor samples for assessing PD-L1 expression and overall survival: An updated analysis of KEYNOTE-010 trial. Ann. Oncol. 2019, 30, 281-289. [CrossRef]

76. Hirsch, F.R.; McElhinny, A.; Stanforth, D.; Ranger-Moore, J.; Jansson, M.; Kulangara, K.; Richardson, W.; Towne, P.; Hanks, D.; Vennapusa, B.; et al. PD-L1 immunohistochemistry assays for lung cancer: Results from phase 1 of the Blueprint PDL1 IHC Assay Comparison Project. J. Thorac. Oncol. 2017, 12, 208-222. [CrossRef] [PubMed]

77. Tsao, M.S.; Kerr, K.M.; Kockx, M.; Beasley, M.B.; Borczuk, A.C.; Botling, J.; Bubendorf, L.; Chirieac, L.; Chen, G.; Chou, T.Y.; et al. PD-L1 immunohistochemistry comparability study in real-life clinical samples: Results of Blueprint Phase 2 Project. J. Thorac. Oncol. 2018, 13, 1302-1311. [CrossRef] [PubMed]

78. Blueprint Working Groups. A Blueprint Proposal for Companion Diagnostic Comparability; Blueprint Working Groups: Washington, DC, USA, 2015.

79. Heery, C.R.; O’Sullivan-Coyne, G.; Madan, R.A.; Cordes, L.; Rajan, A.; Rauckhorst, M.; Lamping, E.; Oyelakin, I.; Marté, J.L.; Lepone, L.M.; et al. Avelumab for metastatic or locally advanced previously treated solid tumours (JAVELIN Solid Tumor): A phase 1a, multicohort, dose-escalation trial. Lancet Oncol. 2017, 18, 587-598. [CrossRef] 
80. Gulley, J.L.; Rajan, A.; Spigel, D.R.; Iannotti, N.; Chandler, J.; Wong, D.J.L.; Leach, J.; Edenfield, W.J.; Wang, D.; Grote, H.J.; et al. Avelumab for patients with previously treated metastatic or recurrent non-small-cell lung cancer (JAVELIN Solid Tumor): Dose-expansion cohort of a multicentre, open-label, phase $1 \mathrm{~b}$ trial. Lancet Oncol. 2017, 18, 599-610. [CrossRef]

81. Barlesi, F.; Vansteenkiste, J.; Spigel, D.; Ishii, H.; Garassino, M.; de Marinis, F.; Özgüroğlu, M.; Szczesna, A.; Polychronis, A.; Uslu, R.; et al. Avelumab versus docetaxel in patients with platinum-treated advanced non-small-cell lung cancer (JAVELIN Lung 200): An open-label, randomised, phase 3 study. Lancet Oncol. 2018, 19, 1468-1479. [CrossRef]

82. Feng, Z.; Schlichting, M.; Helwig, C.; Chand, V.K.; Gelb, A.; Jin, H.; Grote, H.J. Comparative study of two PD-L1 expression assays in patients with non-small cell lung cancer (NSCLC). J. Clin. Oncol. 2017, 35 (Suppl. 15), e20581. [CrossRef]

83. Verschraegen, C.F.; Jerusalem, G.; McClay, E.F.; Iannotti, N.; Redfern, C.H.; Bennouna, J.; Chen, F.L.; Kelly, K.; Mehnert, J.; Morris, J.C.; et al. Efficacy and safety of first-line avelumab in patients with advanced non-small cell lung cancer: Results from a phase $\mathrm{Ib}$ cohort of the JAVELIN Solid Tumor study. J. Immunother. Cancer 2020, 8, e001064. [CrossRef]

84. Updated Information on Sotorasib Dose-Comparison Study. Available online: https://ascopost.com/news/april-2021/updatedinformation-on-sotorasib-dose-comparison-study / (accessed on 10 June 2021).

85. Redig, A.J.; Jänne, P.A. Basket trials and the evolution of clinical trial design in an era of genomic medicine. J. Clin. Oncol. 2015, 33, 975-977. [CrossRef] 